\title{
Genealogia e Etnomatemática: uma aproximação em prol da insurreição dos saberes sujeitados
}

\author{
Genealogy and Ethnomathematics: An Approach in Favor of the \\ Insurrection of Subjugated Knowledge
}

Valdir Damázio Júnior ${ }^{1}$

\begin{abstract}
Resumo
Neste artigo abordaremos as contribuições do pensamento genealógico de Michel Foucault para a Etnomatemática. A genealogia, conforme Foucault, problematiza o que é considerado como certo e seguro, além disso, busca uma insurreição dos saberes que foram sujeitados pelos discursos científicos hegemônicos. Nosso principal objetivo é estabelecer um diálogo entre a genealogia e a Etnomatemática com o intuito de traçar elementos que possibilitem uma insurreição dos saberes matemáticos que foram sujeitados pelo discurso da Matemática científica no âmbito da educação matemática. Este diálogo permite em um primeiro momento problematizar a aceitação de uma pretensa matemática universal que se impõe como verdadeira ditando o que deve ser ensinado como Matemática e, além disso, possibilita o aparecimento de diferentes saberes matemáticos sujeitados.
\end{abstract}

Palavras-chave:Genealogia. Etnomatemática. Insurreição dos Saberes Sujeitados. Educação Matemática.

\begin{abstract}
This study addresses the thought of Michel Foucault's genealogy for the Ethnomatematics. The genealogy problematizes what is considered true and seeks an insurrection of subjugated knowledge by a hegemonic scientific discourse. Based on this perspective, our main goal is to establish a dialogue between genealogy and Ethnomatematics in order to trace elements that make an insurrection of mathematics knowledge that have been subjugated by modern scientific discourse of mathematics, in the context of mathematics education. The dialogue between genealogy and Ethnomatematics allows us to problematize the acceptance of a universal mathematics that dictates what should be taught and, furthermore, makes possible for the appearance of different mathematics subjugated knowledge.
\end{abstract}

Keywords: Genealogy. Ethnomathematics. Insurrection of Subjugated Knowledges. Mathematics Education.

\footnotetext{
${ }^{1}$ Mestre em Educação Científica e Tecnológica pelo Programa de Pós-Graduação da Universidade Federal de Santa Catarina (UFSC). Professor do Centro de Ciências Tecnológicas da Universidade do Estado de Santa Catarina (UDESC), Joinville, SC, Brasil. Endereço para correspondência: Rua Paulo Malschitzki, s/n, Campus Universitário Prof. Avelino Marcante, Bairro Zona Industrial Norte, CEP 89219-710, Joinville, SC, Brasil. Email:valdir.udesc@gmail.com
} 


\title{
1 Introdução
}

Os estudos realizados por Michel Foucault ${ }^{1}$, mesmo depois de quase 30 anos de sua morte, continuam influenciando diversas pesquisas. A abrangência do pensamento foucaultiano faz com que essa influência atinja vários campos do conhecimento, tais como educação, psicologia, epistemologia, linguística, história, direito, ciências sociais, arquitetura, filosofia dentre outras, possibilitando profundas discussões nestas áreas.

Este enorme impacto de Foucault no pensamento contemporâneo deve-se tanto as suas inovadoras formas de análise como também aos resultados obtidos a partir destas. Principalmente porque rompem com a forma anterior de se pesquisar e teorizar, não mais presa e restrita a métodos e teorias fixas.

\begin{abstract}
Não tenho teoria geral e tampouco tenho um instrumento certo. Eu tateio, fabrico, como posso, instrumentos que são destinados a fazer aparecer os objetos. [...] Procuro corrigir meus instrumentos através dos objetos que penso descobrir e, neste momento, o instrumento corrigido faz aparecer que o objeto definido por mim não era exatamente aquele (FOUCAULT, 2006, p. 228).
\end{abstract}

Muitos pensadores ficam fechados em suas ideias e metodologias. Foucault, ao contrário, foi um filósofo aberto que não se ateve a uma única vertente epistemológica ou a uma escola, mas sempre colocou essas categorias em questão. Segundo Foucault (2006, p. 251), “o papel da teoria, hoje, parece-me ser justamente este: não formular a sistemática global que repõe tudo no lugar, mas [...] edificar pouco a pouco um saber estratégico.”

A partir de seus primeiros estudos, Foucault já se interessa pelas condições que possibilitaram o surgimento de determinadas verdades em contraposição a outras manifestações de conhecimento que nunca alcançaram ou que perderam seu status de verdadeiro ao longo da história. Preocupa-se por estudar de que maneira certos discursos passam a constituir-se em modelos científicos, ou seja, elucida a constituição dos saberes, inclusive as possibilidades históricas do surgimento das ciências modernas.

\footnotetext{
${ }^{1}$ Paul-Michel Foucault nasceu em Poitiers, na França, em 15 de outubro de 1926 e faleceu no dia 25 de junho de 1984, em plena produção intelectual. O autor publicou as seguintes obras: Doença mental e psicologia (1954); História da loucura (1961); Raymond Roussel (1963); O nascimento da clínica (1963); As palavras e as coisas (1966); A arqueologia do saber (1969); Vigiar e punir (1977); A vontade de saber - História da sexualidade I (1976); O uso dos prazeres - História da sexualidade II (1984); O cuidado de si - História da sexualidade III (1984). Também são publicadas, hoje em dia, transcrições de seus cursos realizados no Collège de France. Além disso, podemos destacar a Coleção Ditos e Escritos, coletânea de artigos, prefácios, entrevistas, seminários e discursos, publicada em francês (1994) em dois volumes e publicada em português em seis volumes (20002002).
} 
Desta forma, as pesquisas realizadas por Foucault são de grande relevância para que se possa adotar uma postura crítica do pensamento e assim problematizar o que é dado como inquestionável, inclusive a aceitação de uma única Matemática apta a tudo explicar.

A genealogia, segundo Foucault (1999, p. 13), busca problematizar as verdades estabelecidas e assim permitir uma insurreição dos saberes que foram sujeitados por tais verdades.

Entendemos a genealogia não como um assunto que esteja delimitado e particularizado em uma obra ou fase específica do pensamento de Foucault. Pelo contrário, a genealogia é a tática (FOUCAULT, 1999, p. 16) que permeia toda sua obra, desde os primeiros escritos até os últimos, proporcionando em um primeiro momento a problematização do que é considerado como certo e seguro (FOUCAULT, 2009, p. 142).

Fazer genealogia é questionar, repensar, interrogar tudo o que é posto como inquestionável. Não há a Verdade, que se produz no âmbito da purificação dos conceitos, mas a produção da verdade é sempre problemática, situada no entrelaçamento dos acontecimentos locais e singulares, mesmo quando afirma sua universalidade.

A genealogia traz ferramentas para problematizar a questão da verdade e, consequentemente, da verdade científica, bem como analisar como esta verdade se impõe e sujeita outras formas de saberes. É neste ponto que podemos refletir como essas ferramentas genealógicas propostas por Foucault contribuem para os estudos etnomatemáticos comprometidos com uma postura crítica e problematizadora.

Nossa intenção com este trabalho é estabelecer um diálogo entre o pensamento foucaultiano e a Etnomatemática, principalmente no que diz respeito às contribuições da genealogia para os estudos etnomatemáticos. Neste sentido, buscamos refletir sobre e a partir da genealogia visando uma insurreição dos saberes que foram sujeitados pelo discurso da Matemática científica no âmbito da Educação Matemática.

Entendemos a Etnomatemática como um campo de estudos aberto que busca reconhecer como sendo Matemática os saberes produzidos em diferentes culturas. Desta forma não apenas a Matemática científica desenvolvida a partir da modernidade europeia estaria apta a receber o status de Matemática, mas existiriam diferentes matemáticas assim como existem diferentes culturas.

Entretanto, é importante questionar como a aceitação de uma Matemática universal se impõe e sujeita outros saberes matemáticos, de modo a ditar as regras do que deve ser ensinado nas escolas e do que deve ou não ser considerado como sendo Matemática. Para tanto, analisaremos como a genealogia contribui para que a Etnomatemática estabeleça uma 
crítica a essa concepção de Matemática universal e assim permita o aparecimento dos saberes que por ela foram desqualificados.

\section{A produção de discursos científicos verdadeiros e a sujeição de saberes}

Foucault (2000, p. 13) considera que a verdade em nossa sociedade é centrada na forma do discurso científico e nas instituições que o produzem. Além disso, está submetida a uma incitação econômica e política, isto é, necessita-se de verdade tanto para a produção econômica, quanto para o poder político. Essas verdades são produzidas e transmitidas sob o controle, não exclusivo, mas dominante, de alguns grandes aparelhos políticos ou econômicos como universidade, exército, meios de comunicação etc. São objetos de uma imensa difusão e de um imenso consumo, desta forma circula nos aparelhos de educação ou de informação, cuja extensão no corpo social é relativamente grande.

Os discursos científicos postos como verdadeiros sempre trazem consigo efeitos específicos de poder. Um dos efeitos de poder desse tipo de discurso é que, ao se colocar como verdade universal, oculta outros saberes. Na sua aula inaugural no Collège de France, no final de 1970, intitulada A ordem do discurso, Foucault (1996) fala da existência de procedimentos de controle e de delimitação do discurso, procedimentos esses que também são responsáveis por filtrar discursos e assim sujeitar saberes.

O discurso, de acordo com Foucault (1995, p.193), "não é uma consciência que vem alojar seu projeto na forma externa da linguagem; não é uma língua, com um sujeito para falála. É uma prática que tem suas formas próprias de encadeamento e de sucessão." Os discursos, em toda sociedade são produzidos, organizados e redistribuídos por alguns procedimentos que selecionam o que deve ser considerado como saber verdadeiro e excluem os que consideram falsos (FOUCAULT, 1996, p. 8-9).

A principal forma de exclusão de discursos se dá pela prática da oposição entre o verdadeiro e o falso a partir do interior do conhecimento científico, o que Foucault (1996, p. 17) denomina como vontade de verdade. Essa vontade de verdade apoia-se sempre sobre um suporte institucional. Da mesma forma que é reforçada e reconduzida por todo um compacto conjunto de práticas como a pedagogia (o sistema dos livros, da edição, das bibliotecas, como as sociedades de sábios de outrora, os laboratórios hoje), também é reconduzida pelo modo como o saber é aplicado em uma sociedade, como é valorizado, distribuído, repartido e de certo modo atribuído. A vontade de verdade presente no discurso científico tende a exercer 
sobre os outros discursos "uma espécie de pressão e como que um poder de coerção" (FOUCAULT, 1996, p. 18).

O discurso científico qualificado como verdadeiro assim se coloca porque, historicamente, exclui outros discursos, mascarando a vontade de verdade e as relações de poder que o perpassam. Só aparece, dessa forma, aos nossos olhos uma verdade que "seria riqueza, fecundidade, força doce e insidiosamente universal” (FOUCAULT, 1996, p. 20). Em contrapartida, ignora-se a vontade de verdade, "como prodigiosa maquinaria destinada a excluir todos aqueles que, ponto por ponto, em nossa história, procuraram contornar essa vontade de verdade e recolocá-la em questão contra a verdade" (FOUCAULT, 1996, p. 20 21).

Além desses procedimentos de controle e de delimitação do discurso que funcionam como sistemas de exclusão, pode-se falar de outro grupo de procedimentos que funcionam, como "título de princípios de classificação, de ordenação, de distribuição, como se tratasse, desta vez, de submeter outra dimensão do discurso: a do acontecimento e do acaso" (FOUCAULT, 1996, p. 21).

Uma das formas de delimitação do discurso é o que Foucault (1996, p. 33) chama de disciplina. Cada disciplina reconhece proposições verdadeiras e falsas, porém ao mesmo tempo repele para fora de suas margens, toda uma teratologia ${ }^{2}$ do saber. Nesse sentido, no exterior de uma ciência não se pode falar em erros, "porque o erro só pode surgir e ser decidido no interior de uma prática definida; em contrapartida, rondam monstros cuja forma muda com a história do saber" (FOUCAULT, 1996, p. 33).

A história das ciências, portanto, não é a história de descobertas progressivas de verdades apreendidas na relação sujeito-objeto. Para encontrarem-se no verdadeiro as verdades dos discursos científicos, precisam situar-se num plano de exigências complexas e pesadas. As grandes mutações científicas, as grandes descobertas, podem ser lidas como a aparição de novas formas na vontade de verdade a partir de certas relações de poder (FOUCAULT, 1996, p. 16-17).

Há no discurso científico uma relação muito próxima entre poder e saber, da mesma forma uma tentativa de fazer desaparecer o acontecimento e o acaso. Pode-se dizer que há uma polícia ${ }^{3}$ discursiva que visa preservar o horizonte teórico de determinada ciência e ao mesmo tempo, numa determinada época, desqualificar os outros saberes. O que se torna

\footnotetext{
${ }^{2}$ Do grego: teratos: monstro e logos: estudo; narração ou estudo de monstruosidades.

${ }^{3}$ Foucault (1996, p. 35) considera que "não nos encontramos no verdadeiro senão obedecendo às regras de uma polícia discursiva que devemos reativar em cada um de nossos discursos."
} 
evidente e aparece aos nossos olhos é, por conseguinte, uma verdade científica pretensamente separada do poder e dos demais saberes, assim é ocultada a vontade de verdade que atravessa os discursos científicos.

Sobre os discursos excluídos e postos às margens do conhecimento científico, Foucault no curso Em Defesa da Sociedade (1999), mais especificamente na Aula de 7 de janeiro de 1976, chama-os de savoirs assujettis, traduzido para o português como saberes sujeitados ou saberes dominados ${ }^{4}$.

Nesta aula, Foucault (1999, p. 11) explana sobre duas formas de saberes sujeitados. Primeiramente, considera como sujeitados os "conteúdos históricos que foram sepultados, mascarados em coerências funcionais ou em sistematizações formais", ou seja, os "blocos de saberes históricos que estavam presentes e disfarçados no interior dos conjuntos funcionais e sistemáticos." Trata-se de conteúdos do conhecimento histórico meticuloso, erudito. Tais saberes históricos permitem descobrir a clivagem dos enfrentamentos e das lutas que as organizações funcionais ou sistemáticas objetivaram, justamente, mascarar.

Em segundo lugar, toda uma série de saberes desqualificados como saberes não conceituais, saberes insuficientemente elaborados, saberes considerados hierarquicamente inferiores e "abaixo do nível de conhecimento ou da cientificidade requeridos" (FOUCAULT, 1999, p. 12). Foucault (1999, p. 12) os chama de saber das pessoas:

[...] que não é de modo algum um saber comum, um bom senso, mas, ao contrário, um saber particular, um saber local, regional, um saber diferencial, incapaz de unanimidade e que deve sua força apenas a contundência que opõe a todos aqueles que o rodeiam.

Portanto, podem ser considerados sujeitados tanto os saberes sepultados da erudição, como também os saberes singulares, locais, constituídos por conteúdos históricos que foram encobertos pelas sistematizações formais e que foram desqualificados pela hierarquia dos conhecimentos e das ciências (FOUCAULT, 1999, p. 12).

Foucault (1999, p. 15) pergunta:

Quais tipos de saber vocês querem desqualificar no momento em que vocês dizem ser esse saber uma ciência? Qual sujeito falante, qual sujeito discorrente, qual sujeito de experiência e de saber vocês querem minimizar quando dizem: eu, que faço esse discurso, faço um discurso científico e sou cientista?

O discurso científico, por ter se tornado uma verdade hegemônica, aparece então como sendo uma das principais formas a partir da qual os saberes são desqualificados. É esse discurso que, a partir da modernidade, se coloca como único discurso que é capaz de dizer a

\footnotetext{
4 No texto "Genealogia e poder" o termo savoirs assujettis é traduzido como "saberes dominados" (FOUCAULT, 2000, p. 167).
} 
verdade. Assim mascara a vontade de verdade que o atravessa, ocultando as relações de poder que a perpassam. Ao fazer isso, funciona como se fosse uma verdade que, por acreditar ser neutra e imparcial, pode desqualificar qualquer outro saber, considerando-o como erro ou ilusão.

\section{Genealogia e insurreição dos saberes sujeitados}

O objetivo da genealogia, segundo Foucault (1999, p. 13), é reativar os saberes sujeitados, saberes locais, descontínuos, desqualificados, "não legitimados contra a instância teórica unitária que pretenderia filtrá-los, hierarquizá-los, ordená-los em nome de um conhecimento verdadeiro, em nome dos direitos de uma ciência detida por alguns."

Foucault (1999, p. 13-14) afirma que a genealogia não implica um retorno a uma forma de ciência mais atenta ou mais exata. A genealogia é uma anticiência porque se distancia de uma teoria sistemática e se contrapõe aos efeitos de poder de um conhecimento científico. Não que se reivindique o direito lírico à ignorância e ao não-saber, tampouco se trata de pôr em destaque uma experiência que ainda não foi captada pelo saber, mas trata-se de uma ativação dos saberes que foram sujeitados pelas verdades científicas (FOUCAULT, 1999, p. 13-14).

Diante de um saber científico hierarquizador e ordenador, Foucault opta pelo saber genealógico, local e sem pretensões de verdade universal. A este processo Foucault denomina como insurreição dos saberes sujeitados.

No domínio especializado da erudição, tanto como no saber desqualificado das
pessoas, jazia a memória dos combates, aquela, precisamente, que até então tinha
sido mantida sob tutela. E assim se delineou o que se poderia chamar uma
genealogia, ou, antes, assim se delinearam pesquisas genealógicas múltiplas, a um
só tempo redescoberta exata das lutas e memória bruta dos combates; e essas
genealogias, como acoplamento desse saber erudito e desse saber das pessoas, só
foram possíveis, e inclusive só puderam ser tentadas, com uma condição: que fosse
revogada a tirania dos discursos englobadores, com sua hierarquia e com todos os
privilégios das vanguardas teóricas. Chamemos, se quiserem, de 'genealogia' o
acoplamento dos conhecimentos eruditos e das memórias locais, acoplamento que
permite a constituição de um saber histórico das lutas e a utilização desse saber nas
táticas atuais (FOUCAULT, 1999, p. 13).

Trata-se de uma insurreição dos saberes sujeitados, sobretudo contra os efeitos centralizadores de poder que são vinculados à instituição e ao funcionamento de um discurso científico organizado no interior de uma sociedade como a nossa. Pouco importa que esta institucionalização do discurso científico se realize em uma universidade ou, de modo mais 
geral, em um aparelho político (FOUCAULT, 1999, p. 14). São os efeitos de poder próprios a um discurso considerado como científico que a genealogia deve combater.

O sentido histórico para a genealogia escapa à metafísica e não se apoia em nenhum absoluto. Foucault se inspira na ideia nietzscheana ${ }^{5}$ de que, por trás de todo saber, o que está em jogo é a luta pelo poder, deste modo contrapõe-se a tudo que se apresenta como verdadeiro, absoluto, universal, ou seja, se posiciona no outro extremo do que foi apregoado pela tradição filosófica e científica. A pesquisa genealógica percebe a si mesma como um saber perspectivo, localizado, que expõe a memória dos enfrentamentos, das lutas, dos jogos discursivos.

A genealogia não esconde ser um saber perspectivo. O genealogista não pretende ser um observador, neutro, separado da realidade que estuda. "Em vez de fingir um discreto aniquilamento diante do que ele olha, em vez de aí procurar sua lei e a ela submeter cada um de seus movimentos, o olhar perspectivo sabe tanto de onde olha quanto o que olha" (FOUCAULT, 2000, p. 30).

A consciência histórica científica, segundo a máscara que ela usa, se diz neutra, despojada de toda paixão, separada de todo poder, apenas obstinada com a verdade. A genealogia problematiza e, de uma maneira mais geral, interroga toda consciência científica em sua história. Fazendo isso ela descobre então as formas e transformações da vontade de saber, ela descobre a violência das opiniões preconcebidas com relação a tudo aquilo que há de perigoso na pesquisa e de inquietante na descoberta. A análise histórica deste grande querer-saber não se aproxima de uma verdade universal, não se separa das primeiras necessidades que o fizeram nascer para se tornar pura especulação submetida às exigências da razão (FOUCAULT, 2000, p. 35-36).

Ou seja, fazer genealogia não se trata de refletir sobre uma determinada verdade universal, mas sobre os discursos verdadeiros, de forma que cada verdade tem sua história: verdade da loucura; verdade da sexualidade; verdade da prisão; verdade do sistema de educação e verdade da Matemática. Verdades, portanto, localizadas, temporais e não alheias ao poder.

O que Foucault (2006, p.278) busca com a genealogia é fazer uma leitura que possa tornar-se instrumento no seio de lutas possíveis. "Decifrar uma camada de realidade para que

\footnotetext{
${ }^{5}$ Friedrich Nietzsche, filósofo alemão, nasceu em 1844 e faleceu em 1900. Com Nietzsche a filosofia representou uma contrafilosofia. Ao lado de Freud e Marx, rompeu com as tradições morais e assim condenou a filosofia tradicional. Seus trabalhos repercutiram determinantemente sobre vários filósofos, Foucault, talvez seja o principal deles.
} 
dela surjam as linhas de força e de fragilidade, os pontos de resistências e os pontos de ataques possíveis.”

É no interior das relações de saber e poder que há possibilidade de resistência. Se não houvesse tal possibilidade, "de resistência violenta, de fuga, de subterfúgios, de estratégias que invertam a situação", de forma alguma existiria relação de poder (FOUCAULT, 2006b, p.277).

Quero dizer que as relações de poder suscitam necessariamente, apelam a cada instante, abrem a possibilidade a uma resistência e resistência real que o poder daquele que domina tenta se manter com tanto mais força, tanto mais astúcia quanto maior for a resistência (FOUCAULT, 2006, p. 232).

Estudar sobre e a partir da genealogia significa abrir espaço para as resistências, tratase de uma outra perspectiva que se caracteriza primeiro por evidenciar que aquilo que foi qualificado como verdadeiro no âmbito da verdade científica só se tornou possível excluindo o diferente, o falso. Ao se fazer esta crítica, se proporciona espaços de resistência e inversão, justamente por fazer aparecer os discursos silenciados, considerados falsos, inferiores, em nome de um conhecimento pretensamente universalista.

A genealogia proporciona uma espécie de ação para dessujeitar os saberes locais, de forma que estes seriam capazes de oposição e de luta contra a coerção de um discurso teórico unitário, formal e científico. Trata-se de uma reativação dos saberes locais contra a hierarquização científica do conhecimento e seus efeitos de poder intrínsecos (FOUCAULT, 1999, p. 16).

A seguir, buscaremos analisar de que modo esta perspectiva genealógica foucaultiana pode ser articulada com os estudos etnomatemáticos, tanto no sentido de considerar elementos que foram responsáveis por uma sujeição de saberes no campo da Educação Matemática, quanto no sentido de buscar uma insurreição dessas saberes matemáticos sujeitados.

\section{A Educação Matemática: conhecimento matemático científico e sujeição de saberes}

O conhecimento matemático científico imagina ser a verdade única e livre de quaisquer interferências. É nesse sentido que a Matemática é a materialização da racionalidade cartesiana, buscando a verdade através do método e da demonstração, partindo sempre da decomposição do complexo em partes mais simples. O conhecimento é concebido como um processo de encadeamento lógico no qual é necessário partir de conceitos mais 
simples para que se possa chegar à compreensão de conceitos mais complexos, "chegando, assim, às 'verdades' sobre as coisas” (CLARETO, 2003, p.176).

Ao se colocar como uma forma de saber superior, o conhecimento matemático científico sujeita saberes, isto porque esta concepção pautada em uma pretensa Matemática universal nega a legitimidade de todas as outras formas de conhecer que não estão de acordo com seus princípios epistemológicos e suas regras metodológicas.

Tal concepção de Matemática, por conseguinte, influencia a forma como a Matemática deve ser ensinada. A Matemática que supõe uma correspondência perfeita entre ela e o mundo está diretamente relacionada com a aceitação da Matemática como sendo um conhecimento preciso, neutro e universal. Sendo assim, pensar o ensino de Matemática se resumiria a discutir a melhor maneira de transmitir este conhecimento tido como verdadeiro e válido universalmente.

O discurso da Educação Matemática se apropria desta Matemática tida como universal, não apenas em termos cognitivos, mas como um saber considerado, como sendo necessário e presente em todos os lugares. É um saber que se coloca como essencial, pois acredita ser capaz de permitir a plena compreensão do mundo.

É justamente sob essa perspectiva que a escola e a Educação Matemática vêm sendo concebidas e praticadas. Ainda hoje impera na escola a Matemática científica que "se identifica com aquela maneira cartesiana de proceder e de conceber o conhecimento" (CLARETO, 2003, p.177).

A Educação Matemática que segue esta perspectiva só aceita, enquanto objeto pertinente a ser ensinado, aquele que possibilite o acesso a tais verdades ou que possibilite ao aluno uma aproximação delas. Tudo o que não esteja relacionado a este objetivo deve ser descartado como não pertinente de ser ensinado ou mesmo discutido em Educação Matemática.

Nesses moldes, o objetivo da Educação Matemática é:

[...] convencer ideologicamente crianças e jovens de que o conhecimento matemático desenvolvido segundo a tradição grega/europeia é essencialmente verdadeiro, isto é, de fazer com que as pessoas vejam esta forma de matematizar como sendo a única legítima. É deste modo que o conhecimento matemático produzido segundo um modelo de racionalidade é difundido, entre diversos contextos socioculturais, como sendo 'o correto', senão o único, em detrimento de vários outros saberes matemáticos (COSTA; DOMINGUES, 2006, p. 51).

Pensar o ensino equivaleria a pensar sob o olhar permanente e rígido da Matemática científica. Ensinar Matemática seria, portanto, buscar a melhor maneira de se transmitir este conhecimento dado como verdadeiro e que estaria pretensamente livre das relações de poder- 
saber que permeiam toda a esfera da sociedade. A função da Educação Matemática seria pensar as melhores estratégias para se adaptar a Matemática científica à escola, além de não permitir um distanciamento muito grande entre aqueles saberes ensinados pela escola e os saberes da Matemática científica.

A visão de uma única Matemática, única porque tida como verdadeira e corretamente construída, deixa bem clara qual a relação existente entre a Matemática científica, a Matemática escolar e outros saberes matemáticos. A concepção que impera não admite quaisquer saberes que não estejam de acordo com o seu. Pensar em outros saberes matemáticos fora dos domínios da Matemática científica soa como absurdo. Por conseguinte, tanto a Matemática escolar como os outros saberes matemáticos só fazem sentido se estabelecida uma relação com a Matemática científica, seja esta relação uma comparação ou relação de hierarquia.

Ao serem percebidas diferenças entre práticas matemáticas tende-se, ou a não considerá-las como sendo Matemática, ou a hierarquizá-las no interior de um sistema científico. Nesse caso ao entrar-se em contato com circunstâncias que não estão de acordo com as regras aceitas, ao invés de possibilitar problematizações sobre os limites dessa concepção de Matemática e de Educação, busca-se uma forma de enquadrar esta situação com a Matemática dada, ou excluí-los.

Concordamos com Clareto (2002, p. 32) quando coloca que:

A Educação Matemática que se prende a uma visão de matemática hegemônica e universal, com sua História, no singular, pouco tem a dizer ao cidadão contemporâneo, envolto em crises, prestes a se render, a sucumbir, a se entregar à apatia e à passividade.

Uma vez que a Matemática considerada apta a ser ensinada em todos os lugares é a Matemática científica, em muitos casos este ensino é feito sem sequer tomar conhecimento das Matemáticas locais, dos grupos e das pessoas, pois ou são considerados como saberes errôneos ou, na melhor das hipóteses, menos desenvolvidos. Isto resulta, consequentemente, na exclusão e no silenciamento desses saberes. 


\title{
5 A Etnomatemática e a insurreição dos saberes matemáticos sujeitados
}

Ferreira (1997) afirma que depois do fracasso do Movimento da Matemática Moderna $^{6}$, na década de 1970 , surgiu uma forte reação contra a existência de um currículo comum que apresentava a Matemática como um conhecimento universal e caracterizado por divulgar verdades absolutas.

\begin{abstract}
Além de perceberem que não havia espaço na matemática moderna para a valorização do conhecimento que a criança traz para a escola, esses matemáticos inovadores voltaram seus olhares para outro tipo de conhecimento, também ignorado pela escola: o conhecimento do vendedor de rua [...] o dos índios, [...], o conhecimento do pedreiro, do pescador, da criança brincando, da dona de casa cozinhando, etc. (FERREIRA, 1997, p.13).
\end{abstract}

No mesmo contexto que surgem reflexões sobre a diversidade cultural também emerge pela primeira vez o termo Etnomatemática, inicialmente utilizado por Ubiratan D’Ambrósio como oposição a esta visão universalista e hegemônica de Matemática.

D’Ambrósio em seus estudos passa então a ver a Matemática como uma produção cultural e, neste sentido, cada cultura produz sua Matemática com a finalidade de responder a perguntas e solucionar problemas das necessidades específicas de cada grupo.

Desta forma, como toda produção cultural, a Matemática:

[...] tem sua história, nasce sob determinadas condições econômicas, sociais e culturais e desenvolve-se em determinada direção; nascida em outras condições teria um desenvolvimento em outra direção. Pode-se então dizer que o desenvolvimento da matemática é não-linear, como querem alguns matemáticos. (FERREIRA, 2004, p.17).

D’Ambrósio (1993, p.9) coloca que a "Etnomatemática é a arte ou técnica (techné = tica) de explicar, de entender, de se desempenhar na realidade (matema), dentro de um contexto cultural próprio (etno)”. Este autor, fala em um programa etnomatemático.

Indivíduos e povos têm, ao longo de suas existências e ao longo da história, criado e desenvolvido instrumentos de reflexão, de observação, instrumentos teóricos e, associados a esses, técnicas, habilidades (teorias, techné, ticas) para explicar, entender, conhecer, aprender (matema), para saber e fazer como resposta a necessidades de sobrevivência e de transcendência, em ambientes naturais, sociais, e culturais (etnos) os mais diversos. Daí chamarmos o exposto acima de programa etnomatemática(D’AMBRÓSIO, 1997, p.27).

\footnotetext{
${ }^{6}$ O Movimento da Matemática Moderna teve início no Brasil na década de 1960 e estava de acordo com a tendência internacional de modernização do ensino de Matemática. Dentre seus objetivos pode-se destacar "a renovação pedagógica do ensino de Matemática e a modernização dos programas." (SILVA, 2007, p. 51). Visava assim "diminuir as distâncias entre o saber dos matemáticos e aquele dos currículos escolares" (VALENTE, 2006, p. 27-28).
} 
Esta explicação de D’Ambrósio sobre o termo Etnomatemática é bastante conhecida e é importante, a nosso ver, pela junção do prefixo etno à Matemática, tirando assim o status universalista do conhecimento matemático.

D’Ambrósio (1990, p.17-18) afirma que utilizou o prefixo etno num sentido amplo, indo além da ideia de raça, mas sim com um sentido que se refere a toda uma gama de grupos culturais identificáveis, tais como, tribos, grupos sindicais, pequenos grupos, comunidades etc.

Esta ampliação do prefixo etno proposta por D’Ambrósio foi essencial para que fosse possível ter uma melhor compreensão das propostas da Etnomatemática. Isto porque ao considerar que cada grupo cultural constrói seu próprio conhecimento matemático, a Etnomatemática coloca em questão o caráter do conhecimento matemático que se pretende único e universal. Sendo a Matemática uma manifestação cultural ao invés de uma verdade absoluta e válida em todos os lugares, a Etnomatemática considera a existência de diferentes maneiras de se relacionar matematicamente com o mundo, cada uma pertencente a cada grupo cultural. Assim, deixa de fazer sentido acreditar que uma concepção acerca do conhecimento matemático seja considerada superior a outra, isto porque cada conhecimento tem sua validade no contex to em que foi construído (ALMEIDA, 2008, p.26-27).

De forma resumida, a Etnomatemática, inspirada nos estudos de D'Ambrósio, trata a Matemática como uma manifestação cultural como tantas outras: a arte, a língua, os ritos. Assim sendo, diferentes culturas produzem diferentes Matemáticas, ou seja, diferentes maneiras de conceber a Matemática.

A Etnomatemática se configura como uma vertente de pensamento que abre espaço para as diferenças culturais no campo da Educação Matemática. A Etnomatemática adota uma "postura que busca uma relação mais significativa dos alunos com os conhecimentos matemáticos", postura essa que possibilita tratar da "existência de conhecimentos matemáticos diferentes" e dos "preconceitos e relações de poder" que possibilitam a “assunção de um tipo de conhecimento como sendo o único de valor" (COSTA; DOMINGUES, 2006, p. 52- 53).

Busca-se uma perspectiva educacional que vá "além da mera transmissão dos conhecimentos hegemônicos, aqueles que têm sido usualmente chamados 'conhecimentos acumulados pela humanidade"” (KNIJNIK, 2001 p. 18), possibilitando assim a inserção de outros saberes no meio escolar.

Consideramos esta inserção das Matemáticas silenciadas no ambiente escolar como uma das formas de insurreição dos saberes matemáticos sujeitados, pois se coloca em diálogo 
os saberes da Matemática científica com os saberes matemáticos que estão presentes nas mais diversas comunidades e culturas.

Entretanto, tal inserção não significa apenas uma inclusão acrítica, de diferentes saberes que não leva em conta como esses saberes foram excluídos. Para pensar em pesquisas acadêmicas e práticas escolares que visem uma insurreição dos saberes sujeitados é importante problematizar os discursos que sujeitaram as diferentes Matemáticas.

A Etnomatemática pensada a partir de uma perspectiva genealógica implica inicialmente na adoção de uma postura crítica, que questiona o que até agora é considerado como certo, evidente e incontestável acerca do conhecimento matemático e da Educação Matemática.

A Educação Matemática, sob este enfoque, não se restringe ao ensino dos saberes que possibilitam o acesso a uma Matemática científica, tampouco inclui os saberes matemáticos sujeitados em uma lógica de conhecimento que os inferioriza. Pelo contrário, busca por em destaque as lutas, as relações de poder e a vontade de saber que permeiam a construção de uma Matemática universal e o ensino desta. Por demarcar esses lugares de enfrentamento, esses jogos de verdade, proporciona o aparecimento dos saberes que foram sujeitados por este discurso universalista. Neste sentido, a genealogia fornece subsídios que aprofundam o potencial problematizador da Etnomatemática.

Os estudos etnomatemáticos, a partir da postura genealógica, buscam compreender como se relaciona discurso, saber e poder e assim percebem que não há um saber mais verdadeiro que o outro, pois todos os saberes são construídos discursivamente, enquanto alguns são aceitos como verdades inquestionáveis, outros são descartados como falsos.

Além da relevância em considerar como a Matemática científica é apenas uma forma de conhecimento matemático dentre tantas outras formas de matematizar, merece destaque, como se deu a construção dessa Matemática como superior, porque esse saber se impôs como uma verdade universal e sujeitou os demais.

Para isso acreditamos ser importante olhar historicamente para o conhecimento matemático, não como uma ciência livre das relações locais e de poder, como sendo detentora de uma história linear que pode facilmente descartar as interferências e desconsiderar as singularidades históricas. Mas sim como um campo de saber imbricado nas relações de poder e na vontade de saber que o constitui enquanto ciência.

A problematização das verdades se constitui como uma importante ferramenta para a compreensão da educação hoje, possibilitando "compreender como, historicamente, um conjunto de conhecimentos, de valores e princípios foram se tornando hegemônicos" 
(KNIJNIK, 2001, p. 20). Além disso, a problematização das verdades possibilita descontruir a visão universalista do conhecimento matemático, concebendo-o como um acontecimento discursivo e não de forma atemporal e a-histórica.

Portanto, as contribuições da genealogia foucaultiana para a Etnomatemática revelamse no questionamento da supremacia de certos saberes em relação a outros e assim resulta na ruptura com a visão de que o que deve ser ensinado, por ser verdadeiro, é exclusivamente a Matemática científica. O objetivo não é o estudo pretensamente neutro de outras culturas e a simples inserção de saberes matemáticos locais no meio escolar, mas trata de evidenciar as lutas, os enfrentamentos e as construções e sujeições dos discursos no contexto da Educação Matemática.

Pensar a Etnomatemática a partir de uma perspectiva genealógica implica dirigir o olhar para as condições que possibilitaram que determinados saberes passassem a ser considerados como verdadeiros e assim excluíssem os demais. Desta forma, possibilita-se uma abertura de espaço para uma ativação dos saberes locais, menores, isto é, para uma insurreição dos saberes matemáticos sujeitados.

\section{Considerações finais}

Quando sustentado pela concepção hegemônica de Matemática, o discurso da Educação Matemática exclui os saberes que não se encontram amparados por essa lógica da verdade científica. Assim, faz sentido falar em saberes que são sujeitados por tal discurso, saberes locais, culturais, menores etc.

Consideramos importante abrir a Educação Matemática para novas perspectivas educacionais que busquem responder aos problemas da sociedade atual e que busque um reconhecimento e uma valorização dos mais variados saberes, nesse sentido a importância da Etnomatemática, especificamente a partir das contribuições da genealogia foucaultiana.

A Etnomatemática considera o conhecimento matemático científico como uma manifestação cultural e não como verdade universal, válida em todos os lugares. Ao fazer isso proporciona a inserção de diferentes saberes matemáticos no âmbito da pesquisa e do ensino.

A Etnomatemática, pensada a partir da genealogia, além de reconhecer que diferentes culturas possuem diferentes Matemáticas, também busca problematizar a ideia de que existe um conhecimento matemático preciso, neutro e verdadeiro justamente por expor que tal concepção de conhecimento implica na sujeição dos demais saberes. 
Pensar a Etnomatemática a partir da genealogia requer uma postura, uma forma de luta e de resistência que desmascara os discursos científicos hegemônicos que pretendem ditar as regras do que deve e de como deve ser a Educação Matemática.

Considerado genealogicamente, o ensino de Matemática não se resumiria apenas em discutir a melhor maneira de se transmitir um suposto conhecimento universal, tampouco se resumiria em uma inserção ou estudo acrítico de distintos saberes culturais. Trata-se, acima de tudo, da valorização de todas as formas de saberes matemáticos a partir da problematização do discurso científico hegemônico. Assim poderíamos falar, em termos foucaultianos, em uma insurreição dos distintos saberes matemáticos sujeitados.

\section{Referências}

ALMEIDA, M. N. de. Vivências matemáticas: a construção de conhecimentos no cotidiano de um pedreiro. 2008. 158 f. Dissertação (Mestrado em Educação) - Programa de Pós-Graduação em Educação, UFJF, Juiz de Fora, 2008.

CLARETO, S. M. Educação Matemática e contemporaneidade: enfrentando discursos pós-modernos. Bolema, Rio Claro, v. 15, n.17, p. 20-39, maio, 2002.

CLARETO, S. M.Terceiras margens: um estudo etnomatemático de espacialidades em Laranjal do Jari (Amapá).2003. 254 f. Tese (Doutorado em Educação Matemática) - Instituto de Geociências e Ciências Exatas, UNESP, Rio Claro, 2003.

COSTA, W. N. G. DOMINGUES. K. C. de M. Educação Matemática, Multiculturalismo e Preconceitos: que homem é tomado como medida de todos os outros?. Bolema, Rio Claro, v. 19, n. 25, p. 45-69, maio, 2006.

D’AMBRÓSIO, U. Etnomatemática. São Paulo: Ática, 1990.

D’AMBRÓSIO, U. Etnomatemática: um programa. A Educação Matemática em Revista, Blumenau, v.1, n.1, p. 5-11, março, 1993.

D’AMBRÓSIO, U. Educação Matemática: da teoria à prática. 2. ed. Campinas: Papirus, 1997.

FERREIRA, E. S. Etnomatemática: uma proposta metodológica. Rio de Janeiro: MEM/USU, 1997.

FERREIRA, E. S. Etnomatemática: um pouco de sua história. In: FERREIRA, E. S. (Org.).

Etnomatemática na sala de aula. Natal: UFRN, 2004, p. 9-20.

FOUCAULT, M. A arqueologia do saber. Trad. de Luiz Felipe Baeta Neves. 4. ed. Rio de Janeiro: Forense Universitária, 1995.

FOUCAULT, M. A ordem do discurso. Trad. de Laura Fraga de Almeida Sampaio. São Paulo: Loyola, 1996.

FOUCAULT, M. Em defesa da sociedade: Curso do Collège de France (1975-1976). Trad. de Maria Ermantina Galvão. São Paulo: Martins Fontes, 1999. 
FOUCAULT, M. Microfísica do poder. Trad. de Roberto Machado. 15 ed. Rio de Janeiro: Edições Graal, 2000.

FOUCAULT, M. Ditos e escritos IV: estratégia poder-saber. Trad. de Vera Lucia Avellar Ribeiro. 2.ed. Rio de Janeiro: Forense Universitária, 2006.

FOUCAULT, M. Ditos e escritos V: ética, sexualidade, política. Trad. de Elisa Monteiro. 2.ed. Rio de Janeiro: Forense Universitária, 2006b.

FOUCAULT, M. Entrevista con Michel Foucault. Revista de la Asociacíon Española de Neuropsiquiatría, Madrid, v. 29, n. 1, p. 137-144, 2009. Disponível em: $<\mathrm{http} / / /$ scielo.isciii.es/scielo.php?script=sci_arttext\&pid=S021157352009000100010\&lng=es\&nrm=is o>. Acesso em: 08 jun. 2012.

KNIJNIK, G.. Educação matemática, exclusão social e política do conhecimento. Bolema, Rio Claro, v. 14, n. 16, p. 12-28, out. 2001.

VALENTE, W. R. A matemática moderna nas escolas do Brasil: um tema para estudos históricos comparativos. Revista Diálogo Educacional, Curitiba, v. 6, n. 18, p. 19-34, maio./ago. 2006.

SILVA, V. da. Osvaldo Sangiorgi e "O fracasso da matemática moderna" no Brasil. 2007. 134 f. Dissertação (Mestrado em Educação Matemática) - Programa de Pós-Graduação em Educação Matemática, PUC, São Paulo, 2007. 